\title{
Adolescents' experiences of fluctuating pain in musculoskeletal disorders: a qualitative systematic review and thematic synthesis
}

Sonia Khanom ${ }^{1 *}$ D, Janet E. McDonagh ${ }^{1,2}$, Michelle Briggs ${ }^{3}$, Ebru Bakir ${ }^{3}$ and John McBeth ${ }^{1}$

\begin{abstract}
Background: Adolescents with chronic musculoskeletal pain experience daily fluctuations in pain. Although not all fluctuations are bothersome, pain flares are a distinct type of symptom fluctuation with greater impact. Since literature on the experience of pain flares is non-existent, the aim of this review was to (i) synthesise the qualitative literature on adolescents' experiences of fluctuating pain in musculoskeletal disorders in order to (ii) identify knowledge gaps to inform future research on pain flares.

Methods: Electronic databases (CINAHL, MEDLINE, EMBASE, PsycINFO), grey literature and reference lists were searched from inception to June 2018 for qualitative studies reporting adolescents' experiences of pain.

Comprehensiveness of reporting was assessed using the Consolidated Criteria for Reporting Qualitative Health Research. Studies were analysed using thematic synthesis.

Results: Of the 3787 records identified, 32 studies $(n=536)$ were included. Principal findings were synthesised under three key themes: 1) symptom experience, 2) disruption and loss, and 3) regaining control. The first theme (symptom experience) describes adolescent's perception and interpretation of pain fluctuations. The second theme (disruption and loss) describes the physical, social and emotional constraints faced as a result of changes in pain. The third theme (regaining control) describes coping strategies used to resist and accommodate unpredictable phases of pain. Each theme was experienced differently depending on adolescents' characteristics such as their developmental status, pain condition, and the duration of the pain experience.

Conclusions: Adolescents with chronic musculoskeletal pain live with a daily background level of symptoms which frequently fluctuate and are associated with functional and emotional difficulties. It was not clear whether these symptoms and challenges were experienced as part of 'typical' fluctuations in pain, or whether they reflect symptom exacerbations classified as 'flares'. Further research is needed to explore the frequency and characteristics of pain flares, and how they differ from their typical fluctuations in pain. The review also highlights areas relating to the pain experience, symptom management and health service provision that require further exploration to support (Continued on next page)
\end{abstract}

\footnotetext{
* Correspondence: sonia.khanom@postgrad.manchester.ac.uk

'Centre for Epidemiology Versus Arthritis, School of Biological Sciences, Faculty of Biology, Medicine and Health, University of Manchester, 2.706 Stopford Building, Oxford Road, Manchester M13 9PT, UK

Full list of author information is available at the end of the article
}

(c) The Author(s). 2020 Open Access This article is licensed under a Creative Commons Attribution 4.0 International License, which permits use, sharing, adaptation, distribution and reproduction in any medium or format, as long as you give appropriate credit to the original author(s) and the source, provide a link to the Creative Commons licence, and indicate if changes were made. The images or other third party material in this article are included in the article's Creative Commons licence, unless indicated otherwise in a credit line to the material. If material is not included in the article's Creative Commons licence and your intended use is not permitted by statutory regulation or exceeds the permitted use, you will need to obtain permission directly from the copyright holder. To view a copy of this licence, visit http://creativecommons.org/licenses/by/4.0/ The Creative Commons Public Domain Dedication waiver (http://creativecommons.org/publicdomain/zero/1.0/) applies to the data made available in this article, unless otherwise stated in a credit line to the data. 
(Continued from previous page)

more personalised, tailored care for adolescents with chronic musculoskeletal pain.

Keywords: Adolescence, Juvenile arthritis, Chronic pain, Patient experience, Qualitative research

\section{Key messages}

- Chronic musculoskeletal pain frequently fluctuates within and across days

- Pain flares are distinct from typical, everyday fluctuations in pain

- Research is required to explore the characteristics of pain flares that distinguish it from other fluctuations

\section{Background}

Musculoskeletal pain is responsible for approximately $11 \%$ of primary care visits of young people aged $10-24$ years $[1,2]$, and is the most common reason for which they are referred to paediatric rheumatology services [3]. While some pain may have identifiable pathology, the majority of young people do not have inflammatory or other obvious disease processes to explain their pain [4]. In juvenile idiopathic arthritis (JIA), even when there is effective control of disease activity and inflammation young people continue to report significant pain [5-7]. Similarly, in chronic idiopathic pain syndromes (CIPS), which include complex regional pain syndrome and juvenile fibromyalgia [8], there is a lack of consistent correlation between pain and tissue pathology.

Musculoskeletal pain, both inflammatory and noninflammatory, fluctuates within and across days [913]. Not all fluctuations are considered important by individuals, however 'pain flares' are a distinct type of symptom fluctuation with greater impact [14-18]. There is a lack of research into the definition and experiences of pain flares in young people, but studies report periods of significantly increased pain which affect quality of life [19-21]. For example, diary studies report that 66 and $67 \%$ of young people with in JIA and juvenile fibromyalgia, respectively, experienced daily changes in pain intensity $\geq 10$ units on a $0-100$ visual analogue scale [12, 13], with greater changes in pain being associated with lower quality of life $[12,13,22]$. This may present challenges for adolescents at this stage of their development which includes brain maturation, emergence of abstract thinking, establishing relationships outside the family and the gradual process of achieving independence from parents [17].

While findings show that periods of increased pain are commonly experienced among adolescents, little remains known about the nature and experience of pain flares and how they differ from other fluctuations in pain. Due to the paucity of information on living with pain flares, this review aims to identify and synthesise existing qualitative literature on fluctuating musculoskeletal pain as a starting point, in order to identify knowledge gaps to inform future research of pain flares. Noblit and Hare [23] describe two types of qualitative syntheses: integrated reviews that aim to summarise or 'aggregate' findings, and interpretative reviews which aim to interpret findings and generate theory [24, 25]. This review is an aggregated review which seeks to address the following question: what are adolescents' experiences of pain fluctuations in daily life?

\section{Methods}

This systematic review followed the Enhancing Transparency in Reporting the Synthesis of Qualitative Research framework [26]. No review protocol has been previously published.

\section{Eligibility criteria}

To be included, the studies 1) used a qualitative design, 2) included participants with JIA or CIPS (CIPS incudes fibromyalgia, complex regional pain syndrome or chronic pain (pain $\geq 3$ months) that does not have a definite origin like cancer), 3) included participants aged $10-19$ years, or with a mean age within the 10 to 19 year range, as based on the World Health Organisation definition of adolescence [27], or with a mean age within the 10 to 19 year range, 4) reported participants' own experiences of pain, and 5) were reported in English.

\section{Data sources and searches}

Four electronic databases (CINAHL, MEDLINE, EMBASE, PsycINFO) were searched from inception to June 2018, and supplemented with searches of grey literature (OpenGrey, Scopus) and reference lists of relevant studies and reviews. The Population, Exposure and Outcome (PEO) framework [28] was used to direct the development of the search terms: 'Population' was adolescents with JIA or CIPS, 'Exposure' was pain, and 'Outcome' was experience (Table 1). See Additional file 1 for the full search strategy and hits.

\section{Study selection}

Titles and abstracts from the searches were screened by SK against the inclusion criteria. The selected full-text articles were independently reviewed by SK and EB, of 
Table 1 Database search terms using the Population, Exposure and Outcome (PEO) framework

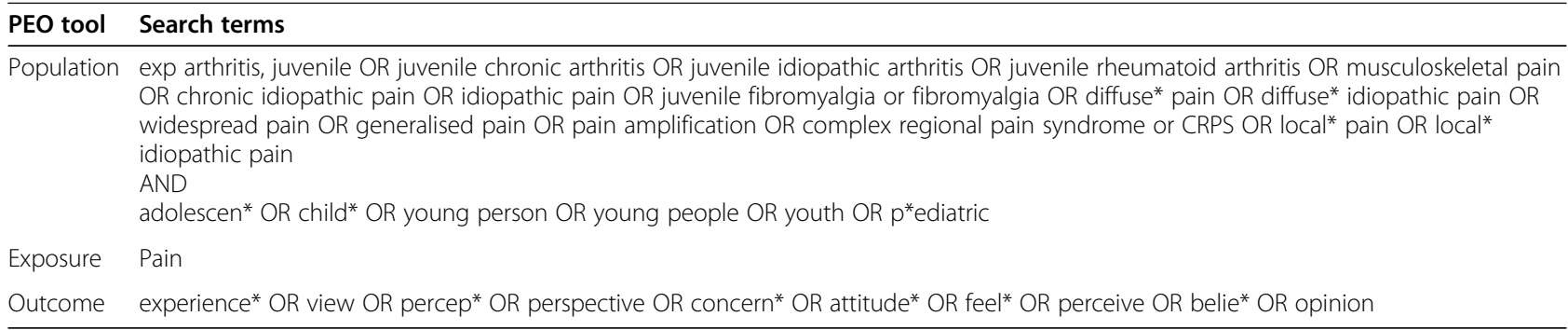

which ineligible articles were excluded. Disagreements were resolved by discussion between SK and EB.

\section{Quality appraisal}

The transparency of reporting was assessed using the Consolidated Criteria for Reporting Qualitative Health Research (COREQ) framework [29]. All disagreements were resolved via discussion.

\section{Data extraction}

Data were extracted on the year of publication, country, participant characteristics, data collection, analysis methods, study purpose, and whether they included data on fluctuating pain.

\section{Data synthesis}

The data were analysed using thematic synthesis outlined by Thomas and Harden [30]. Accordingly, all text under the 'results/findings' or 'discussion/conclusion' section of each article were extracted. Starting with one article, SK performed line-by-line coding of the findings. At least one code was given to all statements relating to pain; example codes included 'cause of pain unknown' 'no sign of swelling' and 'doctors do not understand'. After coding the first paper, a 'bank' of codes was generated which identified aspects of the pain experience and discussed with all authors. Subsequent articles were analysed similarly with new codes being added to the existing bank of codes. Codes were then organised into descriptive themes by grouping the codes based on their similarities and differences. This process involved repeated reference back to the original papers to ensure interpretations were grounded in the words of participants. Examples themes included 'behaviour of health professionals' and 'feeling disbelieved'. Descriptive themes were then further interpreted to develop analytical themes through discussion with all authors. This involved a process of examining and discussing patterns and relationships across descriptive themes, which led to the emergence of more abstract messages and themes that go beyond the content in the original studies. The final themes are discussed below.

\section{Results}

\section{Search results}

A total of 3787 studies were identified (Fig. 1). These were imported into Endnote X8 and the full texts of 95 papers were retrieved and screened for inclusion. Thirtytwo studies fulfilled the inclusion criteria and were included in the review (Table 2).

\section{Study characteristics}

The 32 studies were published from 1983 to 2018 and conducted in 11 countries: United Kingdom [10], United States [8], Canada [4], Sweden [3], Australia [2], Finland [1], Germany [1], Ireland [1], Mexico [1], Norway [1], and The Netherlands [1]. Interviews were conducted in 29 studies, with 9 studies also combining interviews with focus groups, observations, questionnaires, researcher journaling, visual depictions and diaries. One study collected data using only social media posts, one using blog posts and one using focus groups. Eleven studies used a longitudinal approach where interviews/observations were collected at more than one time point.

In total 536 young people with JIA or CIPS participated in the studies, of which 509 had a diagnosis of JIA, and 27 with CIPS. Although all included studies reported adolescents' experience of pain, only 19 studies provide insight into the impact of fluctuating pain on an individual's life and lived experience. 21 studies included data from parents, siblings, health professionals and/or individuals with other chronic illnesses, but efforts were made to only extract data referring to or expressed by adolescents with JIA or CIPS. Ages of young people ranged from 3 to 23 years, but all studies averaged within the adolescent range.

\section{Comprehensiveness of reporting}

The comprehensiveness of reporting was variable, with studies reporting between 10 and 28 of the 32 COREQchecklist items (Table 3). Twenty-five studies provided details on at least $50 \%$ of the criteria.

\section{Synthesis of studies}

Three themes emerged from the synthesis: symptom experience; disruption and loss; and regaining control. 


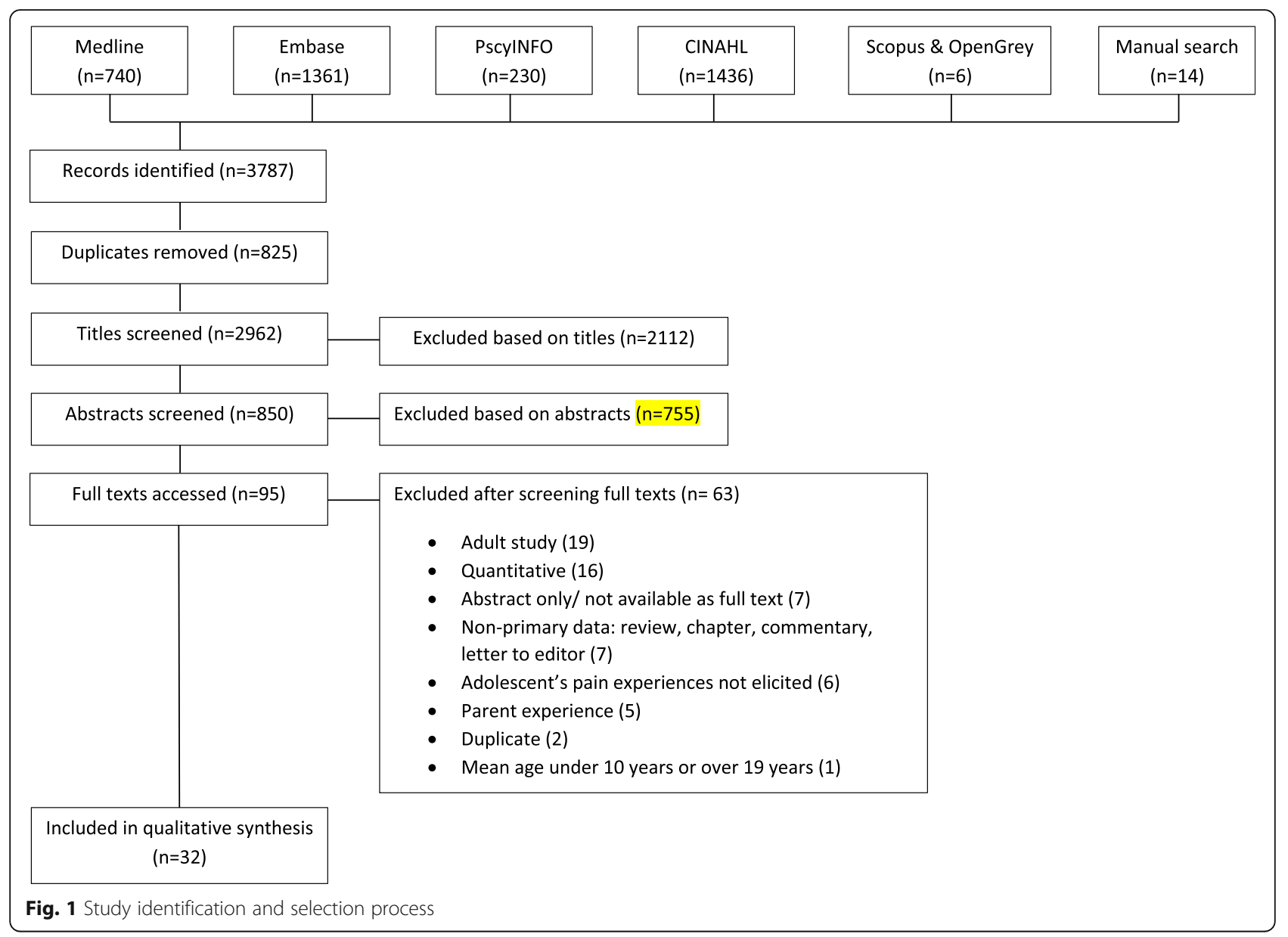

These themes can be seen to describe a journey through which the adolescent experiences fluctuating pain and associated symptoms, encounters the challenges to lifestyle that fluctuating pain presents, followed by employing coping strategies to regain a sense of control. This journey of experiencing pain is not a linear process and the themes are not mutually exclusive. Each stage is experienced differently depending on individual factors such as developmental status, pain condition, and duration of the pain experience (Fig. 2). Quotations corresponding to the themes are shown in Table 4.

\section{Symptom experience}

\section{Fluctuating pain}

Adolescents with JIA and CIPS identified pain as the defining characteristic of their disease $[41,54,61]$. The intensity of pain was described as both constant and varying, such that, although pain was constantly present and experienced at a daily background level, there were periods of heightened perception of pain intensity which could occur regularly or with no logical cause $[59,60]$.

In one study of CIPS, participants referred to these high levels of pain as 'pain attacks' or 'flare-ups', which could occur several times a day and last for hours [60]. Similarly, the term 'flare-up' was used in seven JIA studies, though this time referring to periods of acute disease $[37,38,46,49,53,54,56]$. Little differences were observed between the experiences of disease and pain flares, with both reported to negatively impact adolescents' lives, including their level of confidence, identity and independence in daily living and social activities [37]. They were unpredictable, with participants not knowing what activity might cause intensified disease or pain [37, 60]. Participants described rest, lying down, avoiding activities and using aids such as crutches to manage flares, but when suspected to be a disease flare in JIA, the hospital team were contacted for advice and for potential change in medication $[49,53,56,60]$.

\section{Causes of fluctuating pain}

Adolescents reported feelings of uncertainty about why pain increases [33, 59, 61, 62], but expressed interest in knowing what precipitated them and how to prevent them [54]. In JIA, increased pain was sometimes indicative of disease activity [31, 32, 41], particularly among older adolescents who believed pain to be caused by 


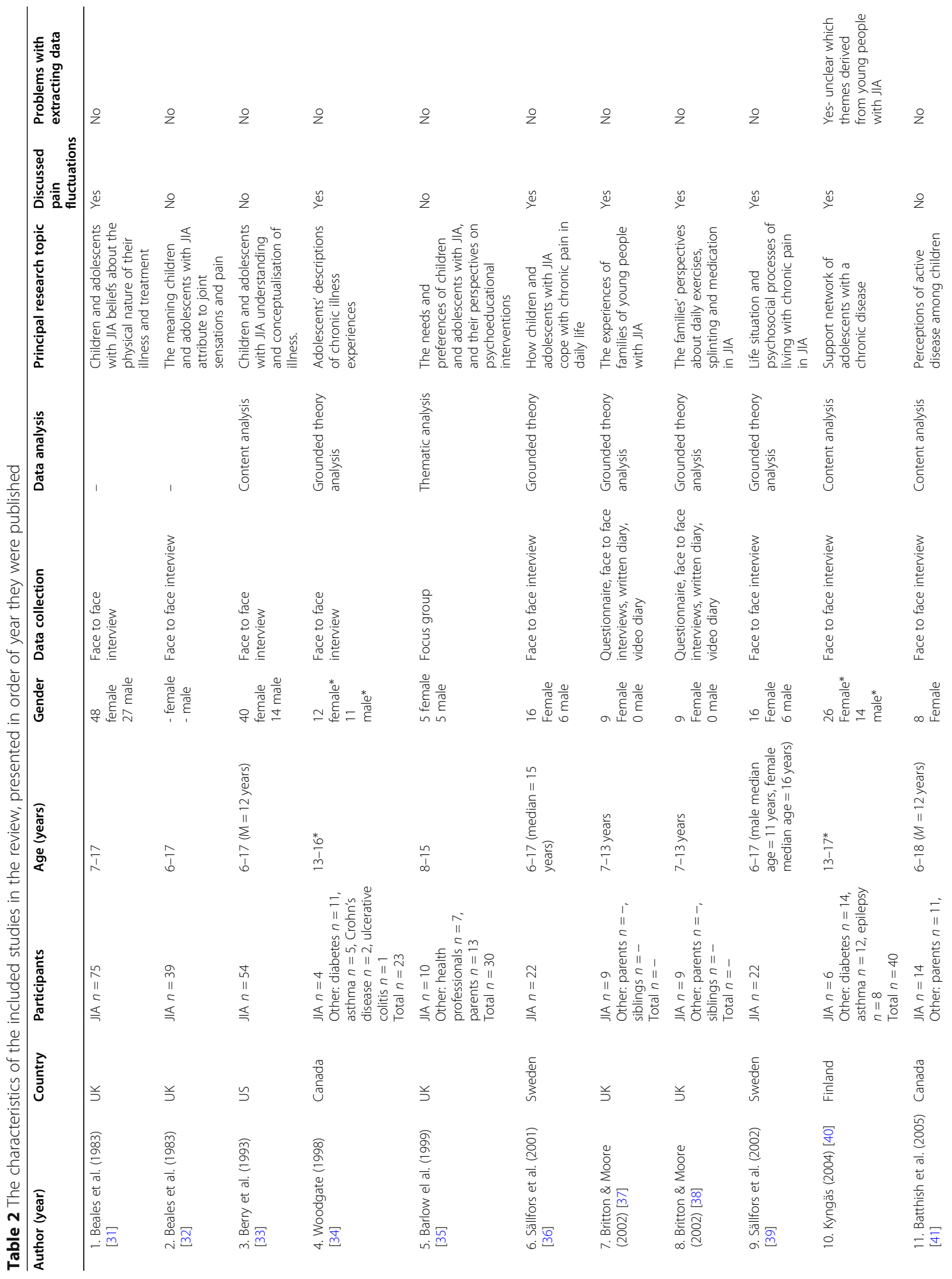




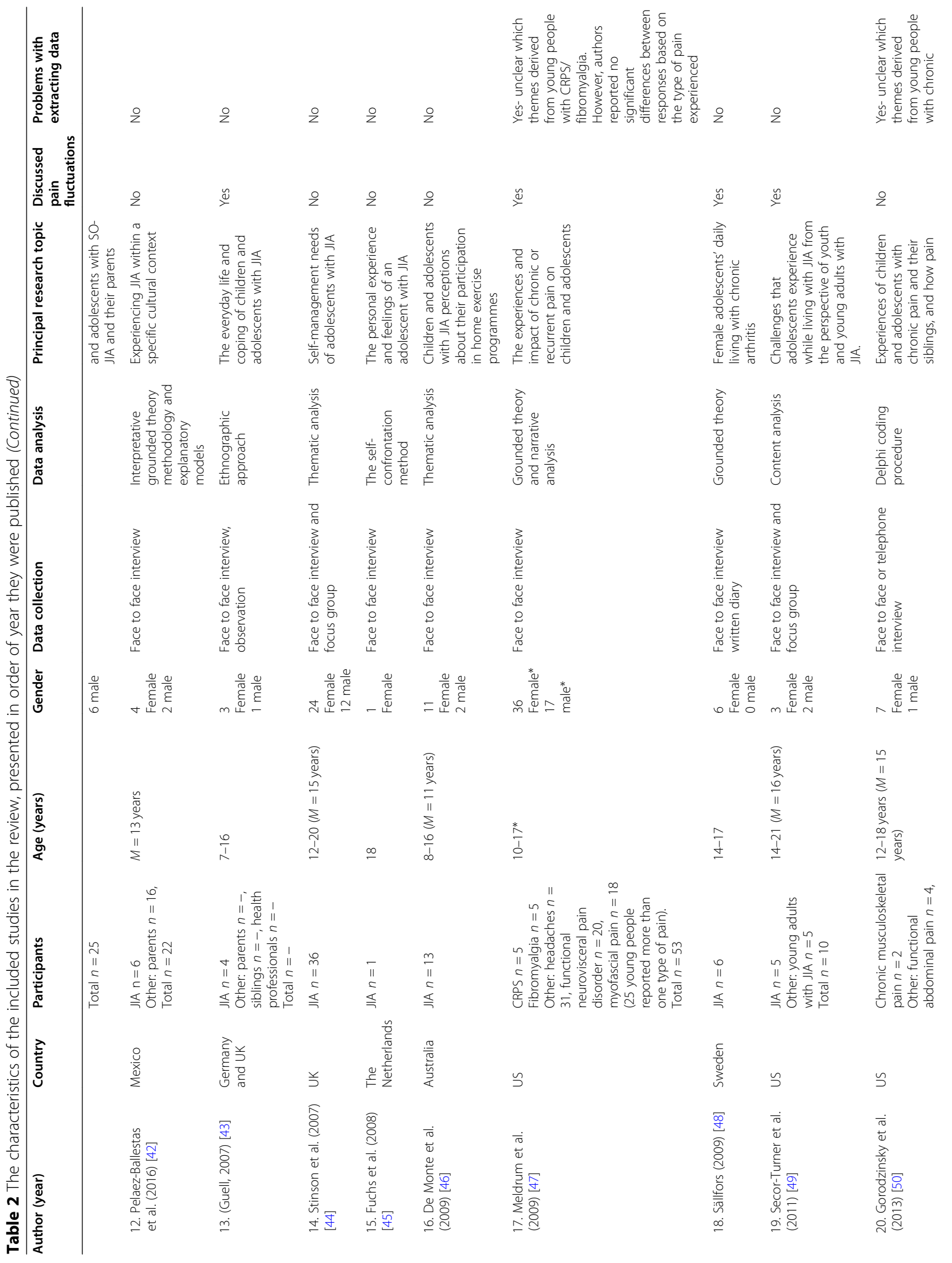




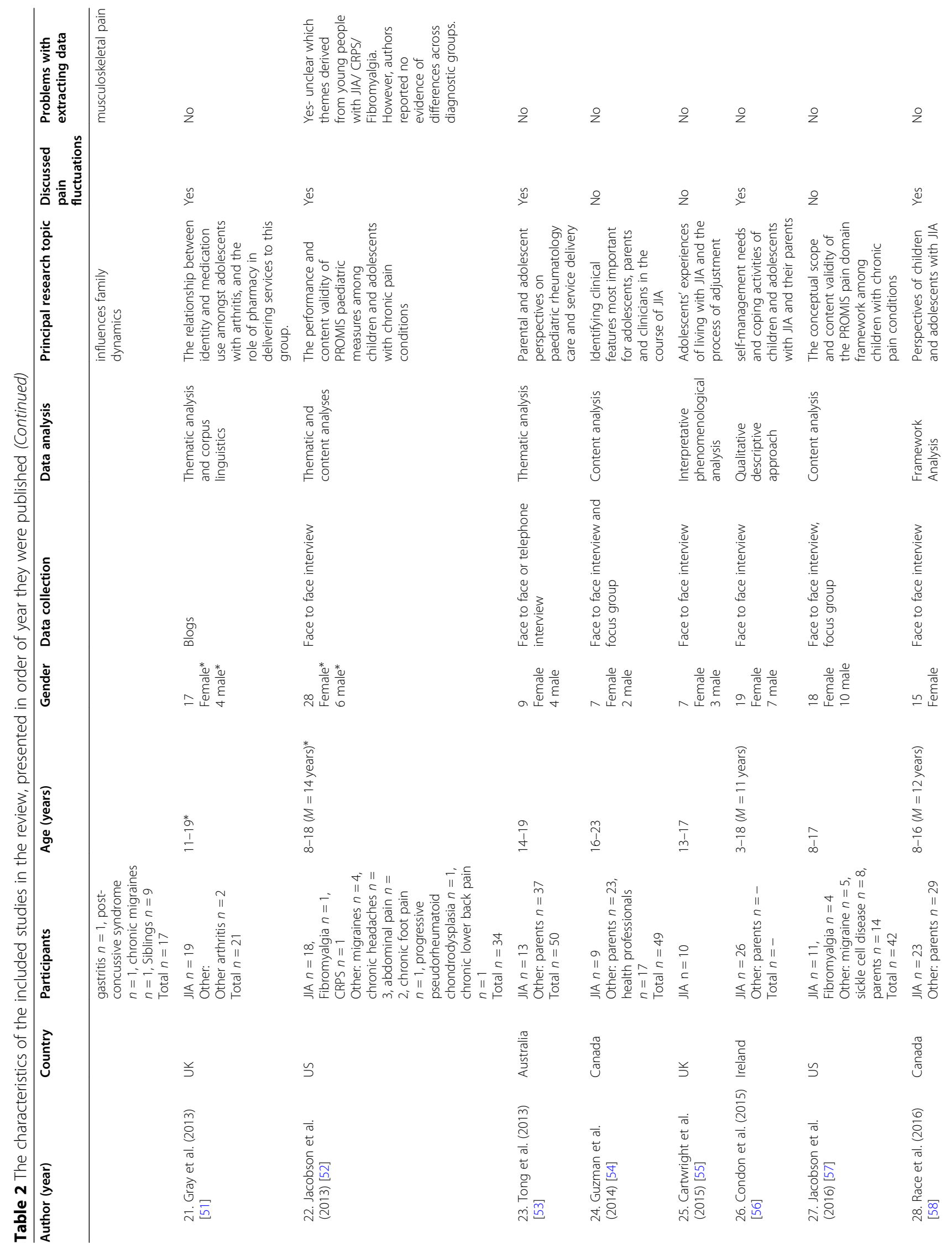




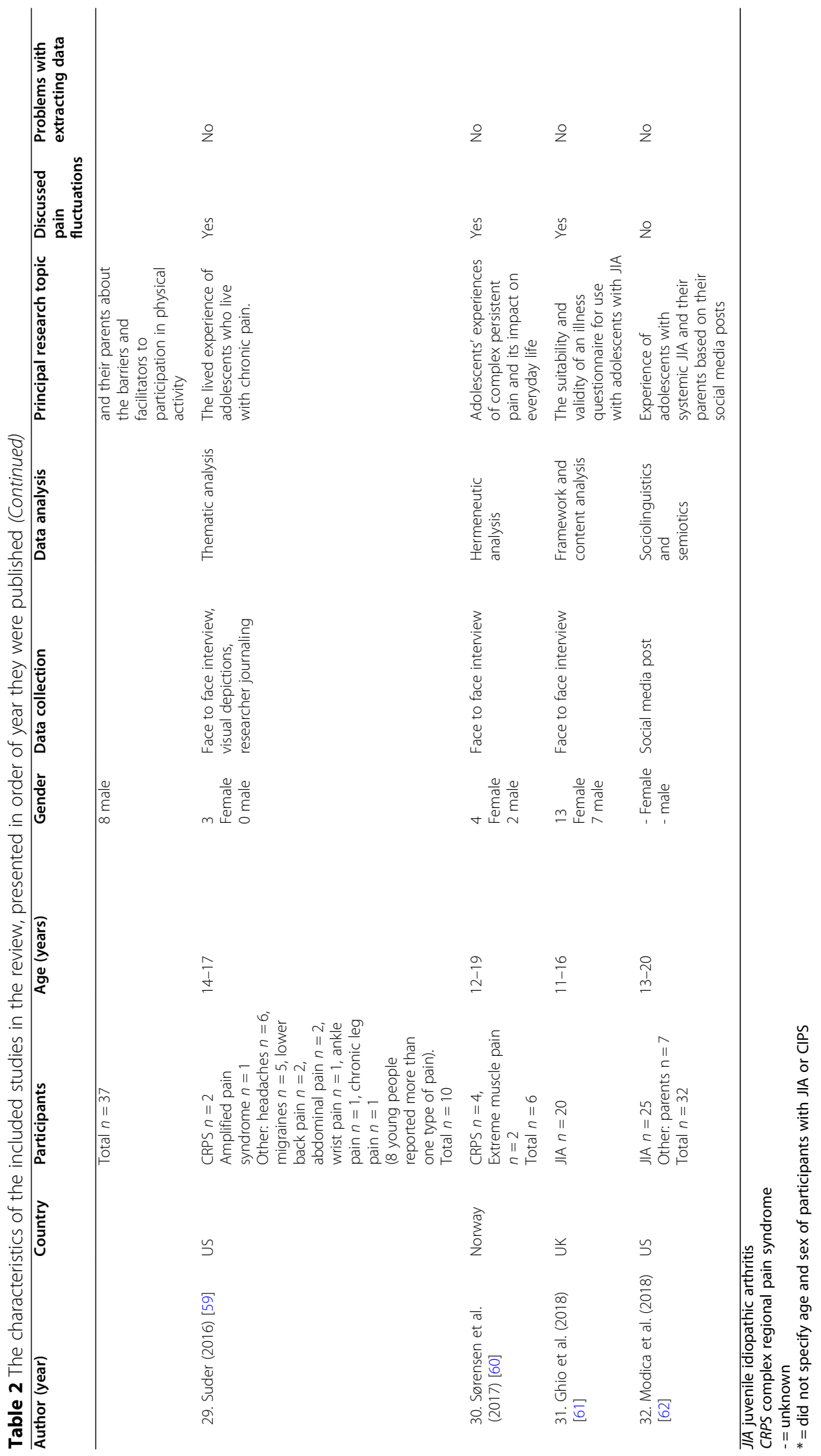


Table 3 Transparency of reporting assessed studies using the COREQ framework

\begin{tabular}{|c|c|c|c|c|c|c|c|c|c|c|c|c|c|c|c|c|c|c|c|c|c|c|c|c|c|c|c|c|c|c|}
\hline \multirow[b]{2}{*}{ Items } & \multicolumn{30}{|c|}{ References } \\
\hline & 44 & 45 & 43 & 48 & 56 & 52 & 37 & 36 & 50 & 62 & 32 & 82 & 55 & 61 & 63 & 41 & 51 & 46 & 39 & 53 & 47 & 38 & 31 & 59 & 40 & 60 & 54 & 35 & 34 & 3 \\
\hline \multicolumn{31}{|c|}{ Domain 1: Research team and reflexivity } \\
\hline $\begin{array}{l}\text { - Interviewer/ } \\
\text { facilitator }\end{array}$ & + & + & + & + & + & + & + & + & + & + & - & + & + & + & - & + & - & + & - & - & - & + & - & + & + & - & + & + & + & - \\
\hline - Credentials & - & - & - & + & - & + & + & + & - & + & - & - & + & + & - & - & + & + & + & - & + & + & - & - & - & + & - & + & - & - \\
\hline - Occupation & + & + & + & + & + & + & + & + & + & - & - & - & + & + & + & + & - & - & + & + & + & + & - & + & + & + & - & - & + & - \\
\hline - Gender & - & - & + & + & - & + & + & + & + & + & - & - & + & + & + & + & + & + & + & + & + & + & + & + & + & + & + & + & + & + \\
\hline $\begin{array}{l}\text { - Experience and } \\
\text { training }\end{array}$ & + & - & - & - & - & - & - & - & - & - & + & - & - & + & - & - & + & - & - & + & + & + & - & + & - & + & - & - & - & + \\
\hline $\begin{array}{l}\text { - Relationship } \\
\text { established }\end{array}$ & + & - & - & + & - & - & - & - & - & - & + & - & + & - & - & + & - & - & - & - & - & - & - & - & - & - & + & + & + & + \\
\hline $\begin{array}{l}\text { - Participant } \\
\text { knowledge of } \\
\text { the interviewer }\end{array}$ & + & - & - & - & - & - & + & - & - & - & - & - & - & - & - & - & - & - & - & - & - & - & - & - & - & - & - & - & - & \\
\hline $\begin{array}{l}\text { - Interviewer } \\
\text { characteristics }\end{array}$ & - & - & - & - & + & - & + & + & - & - & - & - & + & - & - & - & - & - & - & - & - & + & - & - & + & - & - & - & + & \\
\hline
\end{tabular}

\section{Domain 2: Study design}

- Methodological orientation and theory

- Sampling

- Method of approach

- Sample size

- Non-

participation

- Setting of data collection

- Presence of nonparticipants

- Description of sample

- Interview guide

- Repeat

interviews

- Audio/visual recording

- Field notes

- Duration

- Data saturation

- Transcripts

returned

\section{Domain 3: analysis and findings}

- Number of data coders

- Description of the coding tree

- Derivation of themes

- Software

- Participant checking

- Quotations presented 
Table 3 Transparency of reporting assessed studies using the COREQ framework (Continued)

\begin{tabular}{|c|c|c|c|c|c|c|c|c|c|c|c|c|c|c|c|c|c|c|c|c|c|c|c|c|c|c|c|c|c|c|}
\hline \multirow[b]{2}{*}{ Items } & \multicolumn{30}{|c|}{ References } \\
\hline & 44 & 45 & 43 & 48 & 56 & 52 & 37 & 36 & 50 & 62 & 32 & 82 & 55 & 61 & 63 & 41 & 51 & 46 & 39 & 53 & 47 & 38 & 31 & 59 & 40 & 60 & 54 & 35 & 34 & 33 \\
\hline $\begin{array}{l}\text { - Data and } \\
\text { findings } \\
\text { consistent }\end{array}$ & + & + & + & + & + & + & + & + & + & + & + & + & + & + & + & + & + & + & + & + & + & + & + & + & + & + & + & + & + & + \\
\hline $\begin{array}{l}\text { - Clarity of major } \\
\text { themes }\end{array}$ & + & + & + & + & + & + & + & + & + & + & - & + & + & + & + & + & + & + & + & + & + & + & + & + & + & + & + & + & + & + \\
\hline $\begin{array}{l}\text { - Clarity of minor } \\
\text { themes }\end{array}$ & - & - & - & + & - & + & + & + & + & - & - & - & + & + & - & + & - & + & + & - & - & + & - & + & - & - & + & + & + & - \\
\hline
\end{tabular}

their internal pathology (e.g. inflammation) [32]. Younger children showed greater difficulties understanding and conceptualising their pain [31,32] which may be due to cognitive immaturity and not having learnt how to label their experience [37]. In other cases, the cause of increased pain was not perceived by them to be the arthritis, but a result of their behaviour (e.g. overdoing activities), emotions (e.g. stress) and external factors (e.g. cold weather) [33, 49, 61]. For others, particularly young people with CIPS, they were unable to relate the pain to any specific event [60], with pain suddenly occurring "for no reason" [61]. This unpredictability and uncertainty of not knowing what might cause intensified pain appeared to be a source of concern for adolescents with both arthritis and CIPS [59-61].

\section{Fatigue}

Pain and fatigue were found to enter into a feedback loop in which an increase in pain at night disturbed the quantity and quality of adolescents' sleep and led to fatigue in the morning $[48,52]$. Daytime fatigue, in turn, was found to exacerbate pain which further disrupts sleep at night [52].

\section{Psychological distress}

Adolescents' lives were controlled by the uncertainty related to pain [48]. In periods of stability, adolescents saw themselves as normal [34], but getting new pain, or having changes in pain, could lead to feelings of sadness and anxiety especially when it struck with no logical cause $[39,51]$. As a result, young people described emotionally oscillating between feelings of hope to feelings of despair that they had lost control of their pain [39]. It was difficult for young people to be spontaneous which compromised their ability to engage in daily activities and set them apart from their peers. This had a considerable emotional and psychological impact on adolescents as it led to feelings of isolation, difference, and decreased competence [47].

\section{Disruption and loss \\ Restricted body}

All adolescents have to learn to live with a restrictive body which can be described as 'feeling like a ticking fire bomb', where suddenly 'the worst case' could happen [48]. They have to put adjustments in place throughout the day to accommodate and reduce the event of an

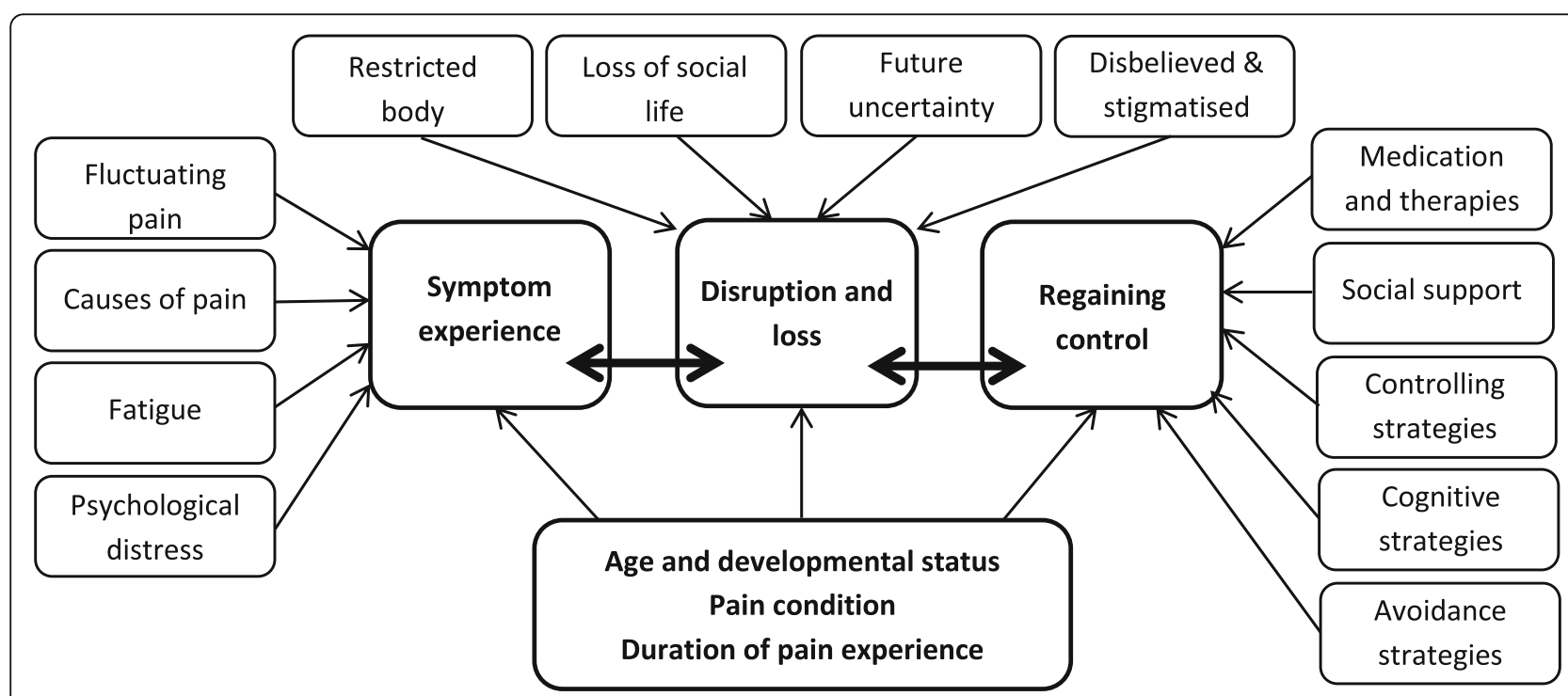

Fig. 2 Themes illustrating adolescents' experiences of fluctuating pain 
Table 4 Quotations from the studies to support the themes

\begin{tabular}{|c|c|}
\hline $\begin{array}{l}\text { Analytical theme/ } \\
\text { subtheme }\end{array}$ & Quotations \\
\hline \multicolumn{2}{|l|}{ 1. Symptom experience } \\
\hline - Pain & $\begin{array}{l}\text { "It was a solid 7, like 24/7, so sometimes it would get up to a 10, like maybe like every other } 2 \text { days but that would still } \\
\text { happen" (female, } 17 \text { years, CRPS) [59] }\end{array}$ \\
\hline - Causes of pain & $\begin{array}{l}\text { "I understand what it is and that it makes everything swell up and like hurt but some stuff I don't know like why it } \\
\text { suddenly can just start hurting for no reason" (female, } 13 \text { years, JIA) [61] }\end{array}$ \\
\hline - Fatigue & $\begin{array}{l}\text { "I think when I'm tired I can feel it (lower back pain) more and I get crankier and I feel like my back hurts "just leave me } \\
\text { alone." When my back injury was really bad I'd only get like a couple hours of sleep and then I'd be tired throughout } \\
\text { the day" (female, } 15 \text { years, CIPS) [52] }\end{array}$ \\
\hline - Psychological distress & $\begin{array}{l}\text { "You get so disappointed, because suddenly you're better... and then you're worse again. All the time you're hoping that } \\
\text { you'll be better... but sometimes you got worse" (participant with JIA) [39] }\end{array}$ \\
\hline \multicolumn{2}{|l|}{ 2. Disruption and loss } \\
\hline - Restricted body & $\begin{array}{l}\text { "It's annoying like just not being able to do things and then having to think ahead about whether I do one thing then I } \\
\text { can't do another thing tomorrow. Not being able to participate in things at school and having to answer people's } \\
\text { questions is also a downside" (female, } 16 \text { years, JIA) [46] }\end{array}$ \\
\hline - Loss of social life & $\begin{array}{l}\text { "I feel I get left out from my friends and everything because } \\
\text { I can't do as many things as they do so they don't even ask } \\
\text { me if I want to come along" (female, } 14 \text { years, JIA) [34] }\end{array}$ \\
\hline - Future uncertainty & $\begin{array}{l}\text { "Like me in tall grass, like enemies around me, and... I don't know where they are, when they're going to attack" } \\
\text { (participant with CIPS) [47] }\end{array}$ \\
\hline $\begin{array}{l}\text { - Disbelieved and } \\
\text { stigmatised }\end{array}$ & $\begin{array}{l}\text { "My peers thought it was strange that one day you arrive on crutches and the next you can hardly walk... and then you } \\
\text { can walk normally... it didn't make sense to them" (participant with JIA) [39] }\end{array}$ \\
\hline \multicolumn{2}{|l|}{ 3. Regaining control } \\
\hline $\begin{array}{l}- \text { Medication and } \\
\text { therapies }\end{array}$ & $\begin{array}{l}\text { "I had, like, a lot of pain in the morning, and then after, like, a lot of walking in the morning it sort of went away" } \\
\text { (female, } 14 \text { years, JIA) [58] }\end{array}$ \\
\hline - Social support & $\begin{array}{l}\text { "They (parents) help me to take good care of my arthritis... sometimes I have very bad pains and my parents help me to } \\
\text { stand them" (participant with JIA) [40] }\end{array}$ \\
\hline - Adapting behaviours & $\begin{array}{l}\text { "I have to watch what I eat or watch what activities I'm doing, planning ahead what I'm going to do for that week so I } \\
\text { don't - see, that's the thing... I plan ahead more than I really want to" (participant with CIPS) [47] }\end{array}$ \\
\hline - Cognitive strategies & "I prepare myself almost every day to wake up having excruciating pain" (female, JIA) [48] \\
\hline - Avoidance pain & $\begin{array}{l}\text { "I want to do what normal teenagers do and not be reminded of my illness all the time. It keeps my mind off the pain } \\
\text { and makes me forget about medication and physiotherapy every now and then. Also people think I am perfectly } \\
\text { healthy when I participate in normal things-and that helps me forget about it" (female, JIA) [43] }\end{array}$ \\
\hline
\end{tabular}

increase in pain [36], however, this increased feelings of being different from peers and set up barriers to what they want to do [36].

\section{Loss of social life}

During times of pain worsening, adolescents describe difficulties engaging in normal social experiences such as sports and going to friends' houses [46, 47, 50, 58, 59, 61], and report impacts on school attendance, concentration and their engagement in school activities [39, 48, 49, 5961]. Being able to participate in education and leisure activities were seen as features of normal adolescence, and an inability to do so may lead to feelings of being different, social isolation, and difficulty building and maintaining an extensive social network $[35,43,48,63,64]$.

\section{Future uncertainty}

Adolescents expressed concerns about how long the pain would last, when it would recur, how it would affect their plans and the long-term prospects of requiring medication $[39,47,53,55,61,62]$. Concerns about the future appeared to be more significant for older compared with younger adolescents [36, 39, 47, 53, 55] who may be more aware of the implications on their lives due to greater abstract thought in middle to late adolescence [32]. Concerns were also expressed more in those who had experienced pain for a shorter period, suggesting that those with longer pain duration may normalise their experiences and learn to adapt their lives to their pain [47].

\section{Disbelieved and stigmatised}

Adolescents faced issues with legitimacy with peers [47, $53,57]$, teachers $[39,53]$, siblings $[50]$ and professionals $[47,60,62]$ when there were no visible signs of pain or disease. Particularly among adolescents with CIPS, when professionals were unable to find an organic cause to their condition and referred them to a psychologist, they 
felt that the pain was perceived to be imagined [60]. This was further compounded by the unpredictable and fluctuating nature of pain, which makes it difficult for others to understand the nature of pain $[44,48,53]$. Individuals took steps to control feelings of stigmatisation, such as choosing not to disclose their pain as they perceived that nobody would understand or believe them $[43,56]$.

\section{Regaining control}

\section{Medication and therapies}

The fluctuating nature of pain was problematic because it could affect adolescents' need for medication and other therapies [51]. Pharmacological treatments were often the first treatment option for pain but could be painful if given by injection, last only a short duration, have unpleasant side effects, and interrupt daily routines $[36,48,61]$. Among the non-pharmacological measures, physical activity was mentioned the most, with some deeming it to be effective at relieving pain and stiffness $[39,44,57,58]$, while others believing it to be an aggravating factor of pain $[31,49]$. Those that viewed physical activity as an aggravating factor of pain were more likely to be newly diagnosed with a pain disorder $[31,46]$, who may not understand that physical activity does not provide immediate pain relief but it is more effective in the long term, as recognised by adolescents who have greater experience of the disease.

\section{Social support}

Positive social support appeared to have a buffering effect on coping with pain [48]. Adolescents relied heavily on their parents for practical and emotional support when they experienced severe pain [40,60], and turned to friends for helping them maintain a sense of normality $[34,48]$. Schools were important for providing practical assistance by means of excusing adolescents from physical education, allowing them to photocopy notes, stay inside during cold weather, and providing extra time to get to their next class $[36,39,53,60]$.

\section{Adapting behaviours}

Older adolescents and those who had experienced pain for longer come to accept that pain is a part of their identity and adapt their lives to the condition [45-47]. To deal with challenges related to unpredictability, they report employing behaviours to resist or accommodate pain including rest, pacing, planning activities and using carefully structured daily routines $[31,43,47,48,56,58,61]$.

\section{Cognitive strategies}

Acquiring knowledge and understanding symptom manifestations were critical aspects in learning to effectively cope with the pain, and helped overcome feelings of helplessness and distress when increased pain was experienced [44, 48, 53]. Engaging in positive thinking also helped minimise the significance of pain $[34,36,45$, $55,59]$, as well as mentally preparing themselves for pain when they 'overdo' activities [48, 61], and ignoring the pain since 'there is nothing you can do about it' [34].

\section{Avoiding pain}

Concealing or minimising pain was common, where adolescents refrained from telling their parents about pain to prevent them from becoming anxious or from hassling them $[47,60]$, and from their peers in order to maintain a positive social identity $[36,46,48,55,59,62]$. Those who were more likely to conceal their pain were in the early to middle phases of adolescence $[46,56]$, while older adolescents were more open about their condition and avoided activities they perceive as potentially pain triggering [36].

\section{Discussion}

Adolescents with chronic musculoskeletal pain experience a daily background of symptoms which frequently fluctuate. When pain is stable, adolescents perceive themselves to be normal and lead lives like their healthy peers. But during unstable periods, that is, periods of heightened perception of symptoms, pain imposed restrictions on their school and social activities which led to a sense of isolation and difference from their peers. Adolescents experienced stigma and misunderstanding from others who have little understanding of how pain can rapidly change, and expressed fear and uncertainty about pain and how it will affect the future. Adolescents implemented various strategies to overcome challenges imposed by unpredictable fluctuations and regain a sense of control.

Our findings are comparable with a recent systematic review which reports six themes in which JIA impacted young people's lives: aversion to being different, striving for normality, stigma and misunderstanding, suspension in uncertainty, managing treatment and a desire for knowledge [65]. In contrast to the latter review, we also found that experiences of pain can be influenced by adolescents' developmental status, pain condition, and duration of pain experience:

\section{Developmental status}

Differences were apparent based on adolescents' developmental status. Feelings of frustration were expressed more strongly by older adolescents, who had greater understanding of the internal physical pathology of pain and were aware of the implications on their lives [32, 36, 39, 53]. To them, pain was a reminder of their disabling condition and the potential ramifications on their future, including their school performance, vocational opportunities, and 
relationship with peers. This greater understanding of pain and its limitations have been found to be a reason why older adolescents with JIA report higher levels of pain than their younger peers [32].

Developmental stage also impacted on the way adolescent's responded to pain, with early to middle age adolescents more likely to internalise or suppress their pain in order to maintain a positive social identity [56]. This is consistent with brain development during this time, in which the prefrontal cortex, which is the site of mature functioning such as long-term planning, decision making and impulse control $[66,67]$, is immature, with development ongoing into early twenties. Its relatively immature control during adolescence may be over-ridden by areas of the limbic system which mature faster and are involved in reward seeking, risk taking and peer interaction [66, 67]. Thus at times of excitement with peers or during crises such as flare, adolescents may regress from abstract to concrete thinking [68] and are less likely to think rationally and cope effectively with their pain [67-70]. This can have consequences for later life as untreated pain in childhood and adolescence can lead to chronic pain in adulthood [71]. A developmentally appropriate approach to pain communication and management is required which considers the impact of biological, psychological, social and vocational factors on individuals' level of understanding. This includes using 'here and now' concrete explanations and avoiding more abstract 'if and when' communications [72]. The skills needed to communicate with young people will vary across all age spectrums, and paediatric, adolescents and adult rheumatologists can benefit from deeper understanding of these differences.

\section{Musculoskeletal pain condition}

Adolescents with JIA and CIPS described difficulties in their search for a diagnosis and gaining empathy and understanding for invisible pain. These broader level findings of uncertainty, not being believed by others and stigma are comparable with young people's experiences of other long-term conditions (e.g. epilepsy, renal failure, inflammatory bowel disease [73-75]), suggesting that attempts to address challenges and disruptions from chronic illnesses can be considered within the same framework [76]. However these difficulties appeared to be more pronounced in young people with CIPS who also faced greater issues with the perception that pain was entirely psychological or 'made-up'. Assessing and managing CIPS can be more challenging and demanding across all age spectrums and part of diagnosing involves ruling out other inflammatory joint conditions which can be frustrating for young people when faced with 'physical symptoms' without a specific treatable medical diagnosis. As a result, participants appear to have greater mistrust in medical providers who could not see or diagnose the cause and had lowered expectations of physician involvement. The perception that pain is undervalued by health professionals has been reported by Lee et al. [77] who found that healthcare professionals had a biomedical understanding of pain, with the assumption that if inflammation and disease processes are managed, the symptom of pain will improve. Improved training for healthcare professionals, including rheumatologists, nurses, physical therapists and occupational therapists, to move beyond a medical model of pain is needed to assist in affirming adolescents' experiences and improve the quality and outcome of clinical relationships. This will include understanding biopsychosocial influences and gaining knowledge in comorbid conditions that can worsen pain (e.g. anxiety, depression).

\section{Pain duration}

Adolescents who are older at pain onset, or have experienced pain for a shorter duration, perceive pain to be greater and find it difficult to adjust to the functional changes and develop effective coping strategies [55, 78]. But as they mature and experience pain for longer, they develop an increasing degree of comfort with their own individuality, normalise their experiences and adapt their lives to their abilities [37, 45-47]. They may also develop tolerance to living with pain the longer they experience it [79] which allows them to push through the pain to achieve their goals e.g. playing sport. In this context, being able to participate in school and social activities were seen as vital to being normal and added to their social identity, which suggests a psychological influence may be present which modulates the perception of pain.

\section{Future directions}

It is a matter of concern that adolescents expressed difficulty and disruption related to having pain despite advances in medical management. It was reported that adolescents faced increased challenges during unstable periods, however, there was a lack of differentiation between whether these periods occurred as part of their 'typical' pain fluctuations, or whether they were symptom exacerbations colloquially referred to as 'flares'. Pain flares have been found, in adult musculoskeletal conditions, to be a complex, multi-layered, whole-body experience that affect quality of life [16-18, 80, 81]. There is currently no published literature on pain flares in the paediatric literature, and clinical measures used to identify disease flares (e.g. inflammatory markers, active joints, etc.) have limited value due to the lack of 
consistent correlation between pain and inflammation in JIA and CIPS [5, 7]. Further research is needed to explore how pain flares are defined and experienced in young people, and how they differ from their normal fluctuations in pain. Individual factors such as developmental status, pain condition, and duration of pain experience would be important determinants to take into account as they can impact how pain is perceived and experienced.

\section{Limitations}

First, the review covered 35 years of research where pain and disease management has changed significantly. Table 2 shows the studies presented in chronological order, but little difference is observed in experiences of pain despite advances in treatment. Second, we included studies with broad age-ranges, which included participants that fall out of the agerange for adolescence. While there were efforts to account for differences based on age and developmental status across some studies [31-33, 36, 39, 46, 47, 49, $52,53,55-58]$, others overlooked the potential influence of these factors on their findings. Third, the review included five studies with pain syndromes other than JIA and CIPS (e.g. headache) [47, 50, 52, 57, 59] and two studies which included chronic conditions not specially related to pain (e.g. asthma) [34, 40]. Of these, we were unable to determine which themes were derived from our target sample in four studies $[40,47,50,52]$, however, two of these reported no evidence of differences across diagnostic groups [47, 52] suggesting that adolescents share many of the same experiences and concerns regardless of the type of illness. Fourth, the studies were conducted in 11 different countries, therefore it is likely that experiences of pain can be influenced by geographical location, culture, race, and ethnicity (e.g. different countries have different pressures to health systems which can affect waiting times for assessment, diagnosis and management) [42, 54, 56]. These views were not analysed separately in this paper.

\section{Conclusions}

The review revealed that adolescents with chronic musculoskeletal pain live with a daily background level of symptoms which frequently fluctuate. It was not clear whether these symptoms and challenges were experienced as part of 'typical' fluctuations in pain, or whether they reflect symptom exacerbations classified as 'flares'. Further research is needed to explore the frequency and characteristics of pain flares, and how they differ from their typical fluctuations in pain. The review also highlighted that pain perception and experience were influenced by adolescents' developmental status, pain condition, and duration of pain experience. It is important that parents and health professionals understand the impact of these differences on young people's experiences in order to facilitate plans for a more personalised approach to pain management.

\section{Supplementary information}

Supplementary information accompanies this paper at https://doi.org/10. 1186/s12891-020-03627-1.

Additional file 1.

\section{Abbreviations}

CIPS: Chronic Idiopathic Pain Syndromes; CRPS: Complex Regional Pain Syndrome; JIA: Juvenile idiopathic arthritis; PEO: Population, Exposure, Outcome

\section{Acknowledgments}

Not applicable

Authors' contributions

SK, JMB, JMD and MB conceived and designed the study. SK and EB performed the data extraction and quality appraisal. SK undertook initial analysis and all authors were involved with interpretation of the data. SK drafted the article and JMB, JMD and MB critically revised it. All authors discussed the results and commented on the manuscript. The author(s) read and approved the final manuscript.

\section{Funding \\ This project was funded by Versus Arthritis grant number 20380, and supported by the National Institute for Health Research Manchester Biomedical Research Centre. The views expressed are those of the authors and not necessarily those of Versus Arthritis, NHS, the NIHR or the Department of Health.}

Availability of data and materials Not applicable.

Ethics approval and consent to participate

Not applicable.

Consent for publication

Not applicable.

Competing interests

All other authors have declared no conflicts of interest.

\section{Author details}

${ }^{1}$ Centre for Epidemiology Versus Arthritis, School of Biological Sciences, Faculty of Biology, Medicine and Health, University of Manchester, 2.706 Stopford Building, Oxford Road, Manchester M13 9PT, UK. ${ }^{2}$ NIHR Manchester Biomedical Research Centre, Manchester University NHS Foundation Trust, Manchester, UK. ${ }^{3}$ Division of Nursing, Midwifery and Social Work, School of Health Sciences, Faculty of Biology, Medicine and Health, University of Manchester, Manchester, UK

Received: 16 January 2020 Accepted: 2 September 2020

Published online: 02 October 2020

References

1. De Inocencio J. Epidemiology of musculoskeletal pain in primary care. Arch Dis Child. 2004 May 1;89(5):431-4.

2. Haller DM, Sanci LA, Patton GC, Sawyer SM. Toward youth friendly services: a survey of young people in primary care. J Gen Intern Med. 2007;22(6): 775-81.

3. McGhee $J$ L, Burks FN, Sheckels $J L$, Jarvis JN. Identifying children with chronic arthritis based on chief complaints: absence of predictive value for 
musculoskeletal pain as an indicator of rheumatic disease in children. Pediatrics. 2002;110(2):354-9.

4. Clinch J, Eccleston C. Chronic musculoskeletal pain in children: assessment and management. Rheumatology. 2008;48(5):466-74.

5. Lomholt JJ, Thastum M, Herlin T. Pain experience in children with juvenile idiopathic arthritis treated with anti-TNF agents compared to non-biologic standard treatment. Pediatr Rheumatol. 2013 May 6;11(1):21.

6. Howite NT, Walco GA, Pochaczevsky R. Assessment of pain in patients with juvenile rheumatoid arthritis: relation between pain intensity and degree of joint inflammation. Ann Rheum Dis. 1992 Mar;51(3):343-6.

7. Thastum M, Herlin T. Pain-specific beliefs and pain experience in children with juvenile idiopathic arthritis: a longitudinal study. J Rheumatol. 2011 Jan 1;38(1):155-60.

8. Sherry DD, Malleson PN. The idiopathic musculoskeletal pain syndromes in childhood. Rheum Dis Clin N Am. 2002 Aug;28(3):669-85.

9. Anthony KK, Schanberg LE. Pain in children with arthritis: a review of the current literature. Arthritis Rheum. 2003 Apr 15:49(2):272-9.

10. Schanberg LE, Gil KM, Anthony KK, Yow E, Rochon J. Pain, stiffness, and fatigue in juvenile polyarticular arthritis: contemporaneous stressful events and mood as predictors. Arthritis Rheum. 2005 Apr 1;52(4):1196-204.

11. Stinson JN, Stevens BJ, Feldman BM, Streiner D, McGrath PJ, Dupuis A, et al. Construct validity of a multidimensional electronic pain diary for adolescents with arthritis. Pain. 2008 Jun;136(3):281-92.

12. Tupper SM, Rosenberg AM, Pahwa P, Stinson JN. Pain intensity variability and its relationship with quality of life in youths with juvenile idiopathic arthritis. Arthritis Care Res (Hoboken). 2013;65(4):563-70.

13. Ghaly MS, Handouka NM, Khashana AK, Shalaby SA, Fahim AE, Ramadan AE. Within-day variability of pain and its relation to quality of life in children with juvenile primary fibromyalgia syndrome. MYOPAIN. 2015 Oct 2;23(3-4): 165-71.

14. Vincent A, Whipple MO, Rhudy LM. Fibromyalgia Flares: A Qualitative Analysis. Pain Med. 2015;17(3).

15. Murphy SL, Lyden AK, Kratz AL, Fritz H, Williams DA, Clauw DJ, et al. Characterizing pain flares from the perspective of individuals with symptomatic knee osteoarthritis. Arthritis Care Res (Hoboken). 2015;67(8): 1103-11.

16. Moverley AR, Vinall-Collier KA, Helliwell PS. It's not just the joints, it's the whole thing: qualitative analysis of patients' experience of flare in psoriatic arthritis. Rheumatology. 2015 Aug 1;54(8):1448-53.

17. Setchell J, Costa N, Ferreira M, Makovey J, Nielsen M, Hodges PW. What constitutes back pain flare? A cross sectional survey of individuals with low back pain. Scand J Pain. 2017 Dec 29;17(1):294-301.

18. Squance ML, Reeves GEM, Bridgman $H$. The lived experience of lupus flares: features, triggers, and management in an Australian female cohort. Int J Chronic Dis. 2014 Nov 23:2014:1-12.

19. Bromberg MH, Connelly M, Anthony KK, Gil KM, Schanberg LE. Self-reported pain and disease symptoms persist in juvenile idiopathic arthritis despite treatment advances: an electronic diary study. Arthritis Rheumatol. 2014 Feb 1;66(2):462-9.

20. Schanberg LE, Anthony KK, Gil KM, Maurin EC. Daily pain and symptoms in children with polyarticular arthritis. Arthritis Rheum. 2003 May 1;48(5):1390-7.

21. Bromberg M. Predictors of sleep quality in children with polyarticular arthritis. Chapel Hill: University of North Carolina; 2009.

22. Dhanani S, Quenneville J, Perron M, Abdolell M, Feldman BM. Minimal difference in pain associated with change in quality of life in children with rheumatic disease. Arthritis Rheum. 2002 Oct 15:47(5):501-5.

23. Agar M. Meta-ethnography: synthesizing qualitative studies. J Nerv Ment Dis. 1990;178(7):466-7.

24. Seers K. What is a qualitative synthesis? J Adv Nurs. 2011;67:2525-61.

25. Booth A, Noyes J, Flemming K, Gerhardus A, Wahlster P, van der Wilt GJ, et al. Structured methodology review identified seven (RETREAT) criteria for selecting qualitative evidence synthesis approaches. J Clin Epidemiol. 2018 Jul;:99:41-52.

26. Tong A, Flemming K, McInnes E, Oliver S, Craig J. Enhancing transparency in reporting the synthesis of qualitative research: ENTREQ. BMC Med Res Methodol. 2012 Nov 27;12:181.

27. McDonagh JE, Gleeson H. In: Watts RA, Conaghan PG, Denton C, Foster H, Isaacs J, Müller-Ladner U, editors. Oxford textbook of rheumatology, vol. 1: Oxford University Press; 2013

28. Bettany-Saltikov J. How to do a systematic literature review in nursing : a step-by-step guide: McGraw-Hill Education; 2012. p. 194.
29. Tong A, Sainsbury P, Craig J. Consolidated criteria for reporting qualitative research (COREQ): a 32-item checklist for interviews and focus groups. Int J Qual Heal Care. 2007;19(6):349-57.

30. Thomas J, Harden A. Methods for the thematic synthesis of qualitative research in systematic reviews. BMC Med Res Methodol. 2008 Jul 10;8:45.

31. Beales JG, Holt PJ, Keen JH, Mellor VP. Children with juvenile chronic arthritis: their beliefs about their illness and therapy. Ann Rheum Dis. 1983 Oct:42(5):481-6.

32. Beales JG, Keen JH, Holt PJ. The child's perception of the disease and the experience of pain in juvenile chronic arthritis. J Rheumatol. 1983 Feb;10(1): 61-5.

33. Berry SL, Hayford JR, Ross CK, Pachman LM, Lavigne JV. Conceptions of illness by children with juvenile rheumatoid arthritis: a cognitive developmental approach. J Pediatr Psychol. 1993 Feb;18(1):83-97.

34. Woodgate RL. Adolescents' perspectives of chronic illness: "tt's hard.". J Pediatr Nurs. 1998;13(4):210-23.

35. Barlow JH, Shaw KL, Harrison K. Consulting the "experts": children's and parents' perceptions of psycho-educational interventions in the context of juvenile chronic arthritis. Health Educ Res. 1999 Oct;14(5):597-610.

36. Sällfors C, Hallberg LRM, Fasth A. Coping with chronic pain: in-depth interviews with children suffering from juvenile chronic arthritis. Scand J Disabil Res. 2001;3(1):3-20.

37. Britton CA, Moore A. Views from the inside, part 2: what the children with arthritis said, and the experiences of siblings, mothers, fathers and grandparents. Br J Occup Ther. 2002;65(9):413-9.

38. Britton CA, Moore A. Views from the inside, part 3: how and why families undertake prescribed exercise and splinting programmes and a new model of the families' experience of living with juvenile arthritis. Br J Occup Ther. 2002;65(10):453-60.

39. Sällfors C, Fasth A, Hallberg LRM. Oscillating between hope and despair-a qualitative study. Child Care Health Dev. 2002;28(6):495-505.

40. Kyngas H. Support network of adolescents with chronic disease: adolescents' perspective. Nurs Health Sci. 2004 Dec;6(4):287-93.

41. Batthish M, Schneider R, Ramanan AV, Achonu C, Young NL, Feldman BM. What does 'active disease' mean? Patient and parent perceptions of disease activity in the systemic arthritis form of juvenile idiopathic arthritis (SO-JIA). Rheumatology. 2005;44(6):796-9.

42. Pelaez-Ballestas I, Romero-Mendoza M, Ramos-Lira L, Caballero R, Hernández-Garduño A, Burgos-Vargas R. Illness trajectories in Mexican children with juvenile idiopathic arthritis and their parents. Rheumatology. 2006;45(11):1399-403

43. Guell C. Painful childhood: children living with juvenile arthritis. Qual Health Res. 2007 Sep;17(7):884-92.

44. Stinson JN, Toomey PC, Stevens BJ, Kagan S, Duffy CM, Huber A, et al. Asking the experts: exploring the self-management needs of adolescents with arthritis. Arthritis Rheum. 2008 Jan 15;59(1):65-72.

45. Fuchs CE, Sinnema G, van Geelen SM, Hermans HJ, Kuis W. Self-investigation to explore the impact of juvenile arthritis on adolescent life: a case-study. Patient Educ Couns. 2008 Jul;72(1):163-7.

46. De Monte R, Rodger S, Jones F, Broderick S. Living with juvenile idiopathic arthritis: children's experiences of participating in home exercise programmes. Br J Occup Ther. 2009 Aug 1;72(8):357-65.

47. Meldrum ML, Tsao JCl, Zeltzer LK. "I can't be what I want to be": children's narratives of chronic pain experiences and treatment outcomes. Pain Med. 2009 Sep 1;10(6):1018-34.

48. Sällfors C, Hallberg LR. Fitting into the prevailing teenage culture: a grounded theory on female adolescents with chronic arthritis. Int J Qual Stud Health Well-being. 2009 Jan 12;4(2):106-14.

49. Secor-Turner M, Scal P, Garwick A, Horvath K, Wells CK. Living with juvenile arthritis: adolescents' challenges and experiences. J Pediatr Heal Care. 2011 Sep 1:25(5):302-7.

50. Gorodzinsky AY, Davies WH, Tran ST, Medrano GR, Bernacki JM, Burks LM, et al. Adolescents' perceptions of family dynamics when a sibling has chronic pain. Child Heal Care. 2013 Oct;42(4):333-52.

51. Gray NJ, McDonagh JE, Harvey K, Prescott J, Roberts R, Shaw KL, et al. Arthriting: exploring the relationship between identity and medicines use, and to identify the contribution of medicines and pharmacy services, for the care of young people with arthritis. London: Pharmacy Research UK: 2013

52. Jacobson CJ, Farrell JE, Kashikar-Zuck S, Seid M, Verkamp E, Dewitt EM. Disclosure and self-report of emotional, social, and physical health in 
children and adolescents with chronic pain-a qualitative study of PROMIS pediatric measures. J Pediatr Psychol. 2013;38(1):82-93.

53. Tong A, Jones J, Speerin R, Filocamo K, Chaitow J, Singh-Grewal D. Consumer perspectives on pediatric rheumatology care and service delivery. J Clin Rheumatol. 2013 Aug;19(5):234-40.

54. Guzman J, Gomez-Ramirez O, Jurencak R, Shiff NJ, Berard RA, Duffy CM, et al. What matters most for patients, parents, and clinicians in the course of juvenile idiopathic arthritis? A qualitative study. J Rheumatol. 2014 Nov 1; 41(11):2260-9.

55. Cartwright T, Fraser E, Edmunds S, Wilkinson N, Jacobs K. Journeys of adjustment: the experiences of adolescents living with juvenile idiopathic arthritis. Child Care Health Dev. 2015 Sep;41(5):734-43.

56. Condon C, O'Regan D, MacDermott E, Killeen O. Self-management needs of children with JIA in Ireland: a qualitative survey of families. Eur J Phys. 2017 Oct 2;19(4):237-42.

57. Jacobson CJ, Kashikar-Zuck S, Farrell J, Barnett K, Goldschneider K, Dampier $C$, et al. Qualitative evaluation of pediatric pain behavior, quality, and intensity item candidates and the promis pain domain framework in children with chronic pain. J Pain. 2015 Dec;16(12): 1243-55.

58. Race DL, Sims-Gould J, Tucker LB, Duffy CM, Feldman DE, Gibbon M, et al. It might hurt, but you have to push through the pain. J Child Heal Care. 2016 Dec 25;20(4):428-36.

59. Suder RC. Lived experience of adolescents with chronic pain: a phenomenological study: Nova Southeastern University; 2016.

60. Sørensen K, Christiansen B. Adolescents' experience of complex persistent pain. Scand J Pain. 2017 Dec 29;15(1):106-12.

61. Ghio D, Thomson W, Calam R, Ulph F, Baildam EM, Hyrich K, et al. The prioritization of symptom beliefs over illness beliefs: the development and validation of the pain perception questionnaire for Young people. $\mathrm{Br} J$ Health Psychol. 2018 Feb;23(1):68-87.

62. Modica R, Lomax KG, Batzel P, Cassanas A. Impact of systemic juvenile idiopathic arthritis/Still's disease on adolescents as evidenced through social media posts. Open Access Rheumatol Res Rev. 2018;10:73-81.

63. Kashikar-Zuck S, Flowers SR, Verkamp E, Ting TV, Lynch-Jordan AM, Graham TB, et al. Actigraphy-based physical activity monitoring in adolescents with juvenile primary fibromyalgia syndrome. J Pain. 2010 Sep;11(9):885-93.

64. Kashikar-Zuck S, Lynch AM, Graham TB, Swain NF, Mullen SM, Noll RB. Social functioning and peer relationships of adolescents with juvenile fibromyalgia syndrome. Arthritis Rheum. 2007 Apr 15;57(3):474-80.

65. Tong A, Jones J, Craig JC, Singh-Grewal D. Children's experiences of living with juvenile idiopathic arthritis: a thematic synthesis of qualitative studies. Arthritis Care Res (Hoboken). 2012 Sep 1;64(9):1392-404.

66. Colver A, Longwell S. New understanding of adolescent brain development: relevance to transitional healthcare for young people with long term conditions. Arch Dis Child. 2013 Nov;98(11):902-7.

67. Steinberg L. Risk taking in adolescence: new perspectives from brain and behavioral science. Curr Dir Psychol Sci. 2007;16(2):55-9.

68. Mcdonagh JE, Kaufman M. The challenging adolescent. Rheumatology. 2009;48(8):872-5.

69. Steinberg L. A social neuroscience perspective on adolescent risk-taking Dev Rev. 2008 Mar;28(1):78-106.

70. Crone $E$. The adolescent brain: changes in learning, decision-making and social relations: Routledge; 2016. p. 89.

71. Zeltzer LK, Anderson CT, Schechter NL. Pediatric pain: current status and new directions. Curr Probl Pediatr. 1990;20(8):415-86.

72. O'Hara M. Quality of life issues: Juvenile idiopathic arthritis and young people in Ireland. Ireland: National University of Ireland; 2013.

73. Bailey PK, Hamilton AJ, Clissold RL, Inward CD, Caskey FJ, Ben-Shlomo Y, et al. Young adults' perspectives on living with kidney failure: A systematic review and thematic synthesis of qualitative studies [Internet]. Vol. 8, BMJ Open. BMJ Publishing Group; 2018 [cited 2020 Aug 20]. Available from: /pmc/articles/PMC5781019/?report=abstract.

74. Saunders B. 'It seems like you're going around in circles': recurrent biographical disruption constructed through the past, present and anticipated future in the narratives of young adults with inflammatory bowel disease. Sociol Health IIIn. 2017 Jun 1;39(5):726-40.

75. Chong L, Jamieson NJ, Gill D, Singh-Grewal D, Craig JC, Ju A, et al. Children's experiences of epilepsy: a systematic review of qualitative studies. Pediatrics. 2016 Aug 10;138(3):e20160658.
76. Venning A, Eliott J, Wilson A, Kettler L. Understanding young peoples' experience of chronic illness: a systematic review. Int J Evid Based Healthc. 2008 Sep 1;6(3):321-36.

77. Lee R, Rashid A, Thomson W, Cordingley L. Exploring the prioritisation of pain and its assessment in healthcare professionals managing juvenile idiopathic arthritis: a qualitative study. Rheumatology. 2017 Dec;1:56.

78. Packham J, Hall MA, Pimm TJ. Long-term follow-up of 246 adults with juvenile idiopathic arthritis: predictive factors for mood and pain. Rheumatology. 2002 Dec 1;41(12):1444-9.

79. Thastum M, Zachariae R, Schøler M, Bjerring P, Herlin T. Cold pressor pain: comparing responses of juvenile arthritis patients and their parents. Scand J Rheumatol. 1997;26(4):272-9.

80. Hewlett S, Sanderson T, May J, Alten R, Bingham CO, Cross M, et al. "I'm hurting, I want to kill myself": rheumatoid arthritis flare is more than a high joint count-an international patient perspective on flare where medical help is sought. Rheumatology. 2012;51 (1):69-76.

81. Brophy S, Calin A. Definition of disease flare in ankylosing spondylitis: the patients' perspective. J Rheumatol. 2002;29(5):954-8.

\section{Publisher's Note}

Springer Nature remains neutral with regard to jurisdictional claims in published maps and institutional affiliations.
Ready to submit your research? Choose BMC and benefit from:

- fast, convenient online submission

- thorough peer review by experienced researchers in your field

- rapid publication on acceptance

- support for research data, including large and complex data types

- gold Open Access which fosters wider collaboration and increased citations

- maximum visibility for your research: over $100 \mathrm{M}$ website views per year

At BMC, research is always in progress.

Learn more biomedcentral.com/submissions 